\title{
Reclamações dos consumidores são respondidas com base em estratégias planejadas?
}

\author{
Are strategies deliberately designed as responses to conswner \\ complaints?
}

\begin{abstract}
Resumo
Reclamações de consumidores têm aumentado, apesar de um presumível foco no atendimento das reclamações pelas empresas. A maioria dos trabalhos sobre o assunto se preocupa em destacar a necessidade de resguardar a base de clientes. Neste artigo examinamos se as respostas das empresas atendem às demandas dos consumidores ou se criam estratégias que consideram igualmente outros interesses. Para isso, foi analisada uma amostra das queixas contra empresas de quatro setores econômicos registradas no Procon-SP e as respostas dadas às mesmas, no período relativo a 2007. O levantamento indicou que as empresas praticam a estratégia de represar parte das queixas, para desencorajá-las, mas uma vez que estas são encaminhadas ao Procon faz-se a opção por atender às suas solicitações, mesmo quando não há concordância com a denúncia.
\end{abstract}

Arnaldo Luiz Ryngelblum ${ }^{\mathrm{I}}$ Nadia Wacila Hanania Vianna ${ }^{2}$

Celso Augusto Rimoli ${ }^{3}$

Palavras-chave: Reclamação, Consumidor, Estratégia.

\begin{abstract}
Consumer complaints have been increasing in spite of the presumed focus of firms on handling them. In fact, the major concern of most works on the subject is about keeping the firms' client base satisfied. This article examines whether firms answer consumer complaints or develops strategies that consider other interests. We examined a complaint sample from four industries, referring to 2007, at Procon-SP, along with the responses provided. The data analysis suggested that firms practice a strategy of restraining part of the complaints received in order to discourage them; but that once they arrive at Procon they are satisfied, even when firms disagree with them.

Keyword: Complaint, Consumer, Strategy.
\end{abstract}

\footnotetext{
1 arnaldory@yahoo.com, Brasil. Professor Titular da Universidade Paulista - UNIP. Doutor em Administração de Empresas pela Fundação Getulio Vargas - FGV-SP. Rua Dr. Bacelar, 1212, V. Mariana, CEP: 04026-002 - São Paulo, SP - Brasil. 2 nhvianna@unip.br, Brasil. Professora da Universidade Paulista - UNIP. Doutora em Administração pela Universidade de São Paulo - USP. Rua Dr. Bacelar, 1212, V. Mariana, CEP: 04026-002 - São Paulo, SP - Brasil.

${ }^{3}$ celso.rimoli@gmail.com, Brasil. Professor da Universidade Paulista - UNIP. Doutor em Administração pela Universidade de São Paulo - USPSP. Rua Dr. Bacelar, 1212, V. Mariana, CEP: 04026-002 - São Paulo, SP - Brasil.
}

Recebido em 04.02.2013

Aprovado em 02.04.2013

Revista Administração em Diálogo

ISSN 2178-0080

Programa de Estudos Pós-Graduados em Administração

Pontifícia Universidade Católica de São Paulo 


\section{Introdução}

Os relatórios das organizações de proteção aos consumidores (OPCs) são enfáticos a respeito dos problemas enfrentados por estes em suas relações com os fornecedores de produtos ou serviços. O número de reclamações registradas na Fundação de Proteção ao Consumidor-SP [Procon-SP] cresceu fortemente até 2007 e tem apresentado desde então um aumento equivalente ao do PIB (PROCON-SP, 2ooga; 2OO8a; 2OO7; 2OO6; IPEA, 2OO9). Importantes empresas têm figurado nas listas anuais das empresas mais reclamadas (PROCON-SP, 2009b). O Procon-SP indica que entre 2004-8 o número de atendimentos cresceu mais de IOo\%, e especificamente dentro do segmento denominado Serviços Essenciais (públicos) houve crescimento de $240 \%$ (REVISTA PROCON-SP, 2OO9).

$\mathrm{Na}$ maioria dos casos, os consumidores só se dirigem às agências de proteção depois de já ter tentado resolver seus problemas diretamente com as empresas responsáveis (ESTADÃO, 20O7). O número de reclamações registradas no Procon, em 20O7, representa menos de $\mathbf{~} \%$ das linhas de telefonia fixa em serviço na grande S. Paulo, por exemplo. Podemos supor que o potencial de reclamações seja muito maior, mas muitos desanimam em fazê-las. Aaker e Day (1982, p.7) observaram que "as empresas têm dificuldade em ouvir os seus clientes”. Devido a isto, estes autores afirmam que diversos intermediários surgiram e cresceram rapidamente para representar os consumidores insatisfeitos.

Se assumirmos que nem os consumidores nem a população de empresas têm crescido a taxas anormais, então algumas das causas para o crescimento do número de queixas podem advir dos consumidores, seja um aumento na demanda de produtos ou serviços (o que de fato aconteceu nos serviços essenciais), ou uma maior disposição e conscientização em manifestar sua insatisfação. As empresas, de sua parte, podem incorrer em um aumento na variedade dos problemas que aborrecem os consumidores, além de uma deterioração ou estagnação das condições de atendimento e tratamento das reclamações recebidas.

O maior envolvimento dos consumidores na busca de solução para suas questões e a piora no atendimento são dois fatores que reforçam a pergunta por que as empresas não conseguem corrigir os problemas que causam as reclamações. Se, por outro lado, 
somente houvesse aumento da demanda, o aumento proporcional das reclamações estaria explicado. Porém, mais uma vez, poderíamos questionar a falta de esforço em reduzir proporcionalmente as reclamações.

Supomos que as empresas não chegaram ainda a implantar os procedimentos mais adequados para resolver satisfatoriamente as reclamações, o que nos leva a questionar quais medidas foram adotadas nesse sentido e por que as empresas não são capazes de corrigir suas deficiências internas. Considerando o discurso das empresas sobre a importância de garantir a satisfação do consumidor como um valor organizacional e um elemento importante em sua estratégia competitiva (DAY, 200I), é importante entender o porquê e em que medida o tratamento das reclamações se descola do discurso formal.

Quando consumidores não recebem a atenção indicada pela literatura, é preciso identificar se existem outros modelos teóricos que possam explicar a realidade. Assim, nesse contexto de aumento da insatisfação, o objetivo deste trabalho é avaliar se a direção tomada pelas práticas adotadas de atendimento ao consumidor segue um padrão deliberado ou se não há diretrizes claras.

Dessa forma, a fim de buscar atender ao que foi proposto acima, este artigo revisa a literatura acercada estratégia de atendimento às reclamações, contrastando suas propostas aos conceitos de estratégia empresarial, onde o consumidor é considerado com suas necessidades, porém inserido num contexto que leva em consideração outros participantes e restrições igualmente relevantes à empresa. Com base nisso examinamos uma amostra de reclamações registradas no Procon-SP, contra empresas de telefonia fixa e móvel, bancos e financeiras, que constituem os setores mais reclamados, acompanhadas de suas respectivas respostas, a fim de verificar se aí podem ser distinguidos padrões deliberados em suas práticas.A última seção discute os resultados observados na pesquisa realizada, que indicou que as empresas praticam a estratégia, para algumas reclamações, de deixá-las chegar à intermediação antes de atendê-las. 


\section{Revisão da Literatura}

\section{Tratamento das Reclamações}

A maioria dos trabalhos de investigação sobre a insatisfação do consumidor tem se centrado em torno das características dos queixosos, suas intenções, comportamento e fontes de desagrado. Eles tentam determinar os efeitos das reclamações sobre os consumidores e organizações, e buscam também analisar a eficácia destas últimas em responder aos reclamos (FORNELL; WERNERFELT, I987; GILLY, I987; DOLINSKY, I994; TAX et al., I998). Há estudos que analisam as percepções de satisfação dos consumidores a partir das respostas empresariais (MAXHAM; NETEMEYER, 2002; 2003)

Trabalhos anteriores aos citados relatam uma baixa taxa de reclamação por parte de consumidores insatisfeitos. O relatório TARP (I986) assinala que até 7o por cento de consumidores que tiveram problemas de serviço ou produto não chegaram a se queixar. Bolfing (I989) e Singh (1990) apontaram baixas taxas de clientes insatisfeitos que reclamaram de produtos ou serviços.

Razões pelas quais os consumidores insatisfeitos não se queixam incluem sua percepção de que reclamar não vale a pena e que se queixar não produz um resultado favorável; além disso, alguns consumidores simplesmente não sabem onde e nem como reclamar (RICHINS, I979; TARP, I986). Outras possíveis explicações incluem a dificuldade emocional que as pessoas encontram em se queixar e a inadequação cultural que experimentam ao fazê-lo, pois podem sentir que prejudicam uma empresa mais do que defendem seu próprio interesse.

Vários estudos buscam identificar os elementos necessários para uma estratégia de relacionamento de marketing efetiva, porque se percebeu que o custo de conquistar um novo cliente pode ser muitas vezes maior do que reter um já existente. Da mesma forma, o atendimento inconsistente das demandas pode afetar a confiança numa marca e em suas taxas de retenção (TAX et al., I998; HOFFMAN et al., I995). Homburg, Fürst, e Koschate (20IO) examinaram como a organização dos setores de atendimento das reclamações podem formatar a percepção de justeza dos consumidores. Outros estudos utilizaram conceitos de teoria da justiça para prover resoluções justas a consumidores, usando a mesma lógica, visando reter os consumidores (TAX et al., 1998). 
Fornell e Westbrook (I984), por sua vez, estudaram os obstáculos que costumam ser levantados contra as reclamações, por estas serem consideradas como 'más notícias' para as gerências. Os autores constataram a seletividade, a restrição, bloqueio, redirecionamento das reclamações, prejudicando sua comunicação com setores da empresa responsáveis pela correção ou acerto dos problemas verificados.

Chauvel e Goulart (2007) realizaram uma ampla revisão de trabalhos voltados ao gerenciamento de reclamações e à atuação dos Serviços de Atendimento ao Consumidor (SACs) no Brasil, reunindo contribuições para uma gestão mais efetiva dessa ferramenta, visando oferecer valor superior ao cliente em relação à concorrência. Esses trabalhos examinaram o comportamento dos consumidores relacionados à satisfação e à insatisfação. Dentre estes, Chauvel (2000) analisou o depoimento de consumidores que relataram haver mudanças radicais de postura de empresas depois da venda, passando a desprezar as suas demandas. Chauvel e Goulart (2007) enumeram as potenciais vantagens dos SACs para as empresas principalmente em situações de insatisfação. Em seguida, depois de constatarem que nem sempre as empresas conseguem responder satisfatoriamente aos consumidores, revisam alguns trabalhos brasileiros que buscam identificar as ações organizacionais que mais contribuem para uma percepção favorável do consumidor seja do ponto de vista da satisfação seja da justiça.

Dentre os estudos que apontam estratégias específicas para lidar com as insatisfações, Dolinsky (1994) indica quatro tipos: foco imediato (quando os clientes estão insatisfeitos com o resultado obtido e há uma elevada tensão de insatisfação), aperfeiçoamento do mecanismo de reclamação, aperfeiçoamento de atributos do produto e manutenção da situação atual. Homburg e Fürst (2005) examinaram duas alternativas empresariais para lidar com reclamações, a 'mecanicista', onde a companhia estabelece as diretrizes de como as tarefas envolvidas devem ser executadas, e a 'orgânica', em que a companhia adota valores e normas do mercado. Gilly (I987) examinou respostas e reações às mesmas, depois de constatar que muitas companhias nem mesmo davam-se ao trabalho de responder. $\mathrm{O}$ autor buscou, entretanto, analisar o intervalo de tempo que mais satisfazia o reclamante, segundo o instrumento de resposta utilizado (cartas, telefonemas, etc.). 
A revisão anterior mostrou que apenas alguns dos estudos propõem estratégias para resolver as insatisfações dos consumidores. De toda forma, as propostas em termos de procedimentos e estruturas giram sempre em torno da gestão da reclamação, sugerindo que com a correta implementação da estrutura e recursos é possível uma gestão eficaz. O que aliena a análise de outras questões, oriundas do meio ambiente (WHITTINGTON, 2002) e internas (FORNELL; WESTBROOK, I984), que uma empresa deve tomar em consideração em sua gestão empresarial e que podem influenciar em sua decisão. Ou seja, esses modelos desconsideram outras necessidades e restrições com que a empresa lida além da questão específica.

\section{Estratégia}

Nesta seção examinamos modelos de estratégia, a fim de superar as limitações apontadas anteriormente e analisar de que maneira são capazes de lidar com o consumidor que reclama, na grande maioria das vezes depois de ter adquirido um produto ou serviço, a quem as empresas não respondem satisfatoriamente em muitos casos, o que acaba gerando reclamações.

Autores frequentemente discordam sobre o que consiste exatamente a estratégia e podem discutir a respeito dos diferentes aspectos associados com o conceito, por exemplo, se seu desenvolvimento se dá de forma deliberada ou emergente, entretanto, todos concordam que se trata de um processo intencional (PETTIGREW et al., 2002). Quando os procedimentos de resposta obedecem a algum tipo de planejamento, “a aspiração clássica de tomar decisões racionais" (WHITTINGTON, 2002, p.77), é possível supor que há aí uma prática estratégica. Mintzberg (I978) considera que há estratégia mesmo sem uma afirmação explícita de intenção, quando uma companhia pratica ações padronizadas ao longo do tempo.

Ao tentar definir quais são as estratégias possíveis que as companhias elaboram, Grant (2002, p. 72) afirmou: 
A estratégia de uma empresa é definida pelas respostas a duas questões: onde a firma compete e como compete? A primeira questão (que corresponde àquilo que é chamado estratégia corporativa) trata da abrangência das atividades da firma: em quais produtos, mercados e atividades a firma deve envolver-se? A segunda questão (estratégia de negócio ou competitiva) trata como a firma planeja estabelecer uma vantagem competitiva sobre seus rivais dentro dos mercados em que serve (GRANT, 2002, 0. 72)

Porter (I996, p.62) fala em superar os competidores e ser capaz de "oferecer maior valor aos clientes ou criar valor comparável a um menor custo, ou ambos.” E, também, "Competição estratégica pode ser pensada como o processo de perceber novos posicionamentos que atraem os consumidores de posicionamentos estabelecidos ou obter novos consumidores para o mercado" (PORTER, I996, p.65).

Ao analisarmos as reclamações podemos encontrar respostas padronizadas repetidas ao longo do tempo. Estas respostas são ações que não possuem caráter competitivo, já que as empresas não competem entre si para oferecer um melhor atendimento nesse sentido ao consumidor. Desta forma, teremos aí uma contradição aparente, pois estas ações por sua padronização configuram estratégias sem serem competitivas.

“[...] (A estratégia) trata da questão de como as organizações tomam e interrelacionam suas decisões significativas” (MINTZBERG, I978, p. 934), ou seja, estratégicas. Mintzberg formulou esta definição de estratégia de forma que ela pode englobar também atividades que não sejam de natureza competitiva, tal como ações de responsabilidade social ou lobby por uma regulamentação em associação com um concorrente mesmo. Lawrence (I999) também trabalha com um conceito de estratégia não-competitiva, a estratégia institucional, voltada para definir ou redefinir práticas e estruturas institucionais (GREENWOOD; HININGS, I996).

Dadas as colocações anteriores, o estudo buscou encontrar respostas padronizadas às reclamações dos consumidores repetidas ao longo do tempo. Duas proposições nortearam a pesquisa:

- a repetição do mesmo tipo de resposta a reclamações assemelhadas indicaria um tipo de estratégia; 
- respostas que satisfazem integralmente ou parcialmente ao consumidor, postergadas para a intermediação do Procon e outras entidades também constitui uma estratégia.

Essas proposições não excluem outras possibilidades que podem ser relevantes do ponto de vista das empresas. Por exemplo, recusar qualquer demanda que envolva reembolso. Uma empresa pode também decidir aceitar todos os pedidos, independentemente de sua correção, em função de seu valor reduzido, por exemplo. $\mathrm{Na}$ próxima seção, descrevemos a pesquisa realizada.

\section{Metodologia}

Realizamos pesquisa qualitativa e quantitativa, do tipo exploratório e descritivo, conduzida em duas etapas. Na primeira, levantamos informações sobre o modo como as empresas respondem às reclamações dos clientes, com base em uma amostra nãoprobabilística por quotas, de I40 processos registrados no Procon-SP, relativo ao ano de 2007. Optamos pelos registros junto ao Procon, uma vez que as empresas poderiam eximir-se ou oferecer um relato enviesado. Na segunda, examinamos documentos que relatam fiscalizações, processos, debates e acordos entre empresas e outros atores do campo, que incluem órgãos do governo (p.ex., Anatel, Banco Central, Inmetro) e de proteção ao consumidor (Procon, Idec).

Os processos correspondiam às reclamações feitas às seguintes empresas, pertencentes a quatro setores econômicos distintos: Vivo Claro e Tim (telefonia móvel); Telefonica e Embratel (telefonia fixa); Itaú, Santander e Bradesco (bancos); Itaucard e outras financeiras do Itaú, Santander e Bradesco/Bankpar (financeiras). Estas empresas respondem pela maior parte das operações de seus setores.

A diversificação dos setores levantados visou levar em conta diferenças de práticas empresariais, evitando dessa forma restringir o estudo a práticas específicas. Foram considerados os setores que mais reclamações têm contra si no Procon. Aamostra obtida Foi delimitada e selecionada pelo órgão, classificada por tipo de reclamação. Compuseram a amostra 30 processos da telefonia móvel, 48 da telefonia fixa, 23 de bancos e 39 de financeiras. O número de processos (que podem ser de dois tipos, CIP [carta de informação preliminar] ou FA [denúncia fundamentada]) reflete o maior Revista Administração em Diálogo ISSN 2178-0080 
volume de CoPs em relação às Faz, e, no que se refere ao número de processos em relação a cada empresa, solicitamos aqui também uma proporção em relação ao total de reclamações de 2007 . Partimos do princípio que seria possível avaliar a repetição das respostas empresariais no período considerado.

O processo CIP é elaborado quando um consumidor está insatisfeito com a resposta de uma empresa à sua queixa realizada diretamente com a reclamada, e contéma(s) resposta(s) inicial(is) desta última, que é(são) descrita(s)a partir da perspectiva do consumidor. Nesta mesma etapa, o consumidor declara suas demandas à empresa, a quem o Procon envia uma carta contendo tal teor. A resposta a esta carta constitui uma resposta, desta vez formal, para as denúncias apresentadas.

No caso da empresa não responder, ou não fazê-lo de uma maneira favorável ao consumidor, este pode pedir para dar prosseguimento ao processo administrativo e endereçar, agora, uma FA para a empresa, constituindo-se esta um processo separado da CIP. Quando uma empresa decide deixar chegar a este ponto, seu nome é automaticamente incluído em uma base de dados de reclamações, que fica disponível para consulta ao público, publicada pelo Procon e divulgada pela mídia. Este outro processo tem um formato semelhante ao anterior, no qual constam, nesta fase, o relato da resposta formal à CIP às demandas do reclamante e a resposta final da firma à FA.

As pastas dos processos incluem as declarações das reclamações dos consumidores e algum tipo de prova como contas, registro de contato com call centers, depósitos de pagamentos, etc., além de trazerem as respostas oficiais das empresas, mais a avaliação do Procon, com sua síntese de cada processo. Como as pastas dos processos não podem ser retiradas do Procon, os dados dos processos foram coletados por meio de fotos.

Cabe notar que o Procon é apenas capaz de intermediar conciliações administrativas. Se um acordo não é alcançado neste último estágio, então os consumidores recebem orientações de como dar prosseguimento judicial a seus processos.

Para efeito de anotação do levantamento de informações, construímos quatro tabelas, uma para cada setor, contendo os dados obtidos no Procon relativos a: número de registro de cada processo; nome da empresa reclamada; nome do reclamante; data de 
início do processo; juntamente com o detalhamento da queixa e demandas do consumidor; respostas da empresa durante os contatos iniciais e a resposta depois da CIP. Foram também anotados os casos em que uma CIP já havia sido enviada, mas sua resposta não foi considerada satisfatória e o processo prosseguiu à fase seguinte, a FA (ver exemplos no Quadro I).

A codificação das reclamações teve por base as classificações adotadas pelos Better Business Bureaus americanos [BBBs, associação que reúne empresas que se comprometem com normas sobre as melhores práticas em relação aos consumidores] (BRAFF; LAOGUE, 2004; GARRETT, 2006); o Ofcom (2008), Departamento de Comunicações da Inglaterra; e, o Procon (PROCON-SP, 2008a):

I- Ocorrência de problemas no funcionamento de um produto/serviço;

2- Problemas na comercialização (promessas publicitárias não cumpridas);

3- Problemas administrativos (na cobrança, anotação de itens e outros); e

$4^{-}$Problemas de atendimento (no relacionamento com a empresa).

As respostas organizacionais para queixas incluem as seguintes alternativas:

I) Não reconhece a reivindicação e oferece uma explicação [ou não];

II) Não reconhece a reivindicação, mas satisfaz parcialmente as expectativas as expectativas do consumidor;

III) Reconhece plenamente o pedido e responde as expectativas;

IV) Reconhece integralmente o pedido e responde de forma diferente às expectativas [insatisfatoriamente, insuficientemente];

IV) Reconhece parcialmente o pedido e responde às expectativas dos consumidores;

V) Reconhece parcialmente o pedido e responde de forma diferente às suas expectativas. 
Quadro I - Exemplos de levantamentos de processos

\begin{tabular}{|c|c|c|c|}
\hline Processo-CIP & Depoimento do Consumidor & $\begin{array}{c}\text { Reclamação e } \\
\text { Demanda }\end{array}$ & Resposta da Empresa \\
\hline $\begin{array}{l}\text { CIP 111.381-6/0207 } \\
\text { Telefonica } \\
\text { (Nome do } \\
\text { Consumidor) } \\
16 / 5 / 2007\end{array}$ & $\begin{array}{l}\text { I- Pagamento do valor mensal de } 03 / 07 \text { não foi } \\
\text { anotado (tendo sido paga cf. doc) e linha telefônica } \\
\text { foi bloqueada. Por várias vezes entrou em contato } \\
\text { para solucionar a questão, sem sucesso. }\end{array}$ & $\begin{array}{l}\text { 3- Problema na } \\
\text { contabilização do } \\
\text { pagamento, com } \\
\text { bloqueio de linha }\end{array}$ & $\begin{array}{l}\text { III- Corrigida a contabilização no } \\
\text { cadastro da Cia e providenciado } \\
\text { crédito referente a período de } \\
\text { inoperância da linha. }\end{array}$ \\
\hline Processo-FA & Resposta à CIP & $\begin{array}{c}\text { Reclamação e } \\
\text { Demanda }\end{array}$ & Resposta da Empresa \\
\hline $\begin{array}{l}\text { FA } 137.500-9 / 0807 \\
\text { Tim } \\
\text { (Nome) } \\
19 / 7 / 2007\end{array}$ & $\begin{array}{l}\text { I- Consumidor reclama que nas faturas } 5 \text { e } 6 / 07 \\
\text { constaram itens que não reconhece: serviço de } \\
\text { jogos; Wap fast e ligações para CE/OI. Questionou } \\
\text { junto à operadora, porém apenas a ligação de } \\
\text { longa distância que foi retirada da } 2^{a} \text { via enviada. } \\
\text { Não houve manifestação por parte da empresa à } \\
\text { CIP. }\end{array}$ & $\begin{array}{l}\text { 3- Requer o estorno } \\
\text { dos demais itens } \\
\text { mencionados e } \\
\text { restituição dos } \\
\text { valores cobrados } \\
\text { indevidamente. }\end{array}$ & $\begin{array}{l}\text { II- Operadora confirma que os } \\
\text { serviços originaram-se deste } \mathrm{n}^{0} ; \mathrm{diz} \\
\text { que podem ter sido efetuados por } \\
\text { terceiros/involuntariamente. } \\
\text { Acordo envolveu valores pagos em } \\
\text { duplicidade. }\end{array}$ \\
\hline
\end{tabular}

Na segunda pesquisa levantamos processos administrativos contra empresas de telefonia por parte da Anatel (2OOO) e processos jurídicos por parte de órgãos de defesa do consumidor (IDEC, 2OIO; REVISTA PROCON-SP, 2OO9); reclamações de consumidores no site Reclame Aqui (20Ira; 20IIb); conteúdo de fórum de debate entre empresas, Anatel e órgãos de defesa (ANATEL, 2OIO; 2009; MEDEIROS, 2OIO); relatório do Inmetro (2006) sobre atendimento ao consumidor por parte das empresas de telefonia; relatório do BC (2Orrb); acordo de empresas com o Ministério da Justiça (2OIO; FROUFE, 2OIO); e relatos (FOLHA DE S. PAULO, 2OOI, julho 28) e denúncia da mídia (WIZIAK; SOARES, 2OIO, maio 23), que trazem alguns exemplos de situações de negociação, desacordo e conflito entre os atores citados, o que dá uma indicação sobre seu poder e legitimidade nas questões abordadas.

Para o exame dos referidos textos, buscamos identificar diferentes formatos de relacionamento no campo das reclamações, envolvendo em todos os casos a notificação das empresas por parte de distintos atores, como consumidores, órgãos de regulação governamentais, mídia e organizações civis de defesa do consumidor, que indicam a insatisfação com o atendimento dado às queixas. Para isso utilizamos o método da análise do discurso (FAIRCLOUGH, 20OI), onde a análise textual e a da prática discursiva da produção, distribuição e consumo dos documentos examinados ajudam a identificar se existe prática hegemônica e ideológica da parte de algum ator. 


\section{Análise dos Dados}

A fim de analisar se as respostas (contidas nos processos levantados no Procon) às reclamações encaminhadas pelos consumidores constituem, no conjunto, estratégias empresariais, consideramos que as mesmas são a parte visível da estratégia desenvolvida pela empresa. Assim, analisamos, em primeiro lugar, as reclamações individuais expressas nos processos no Procon. Respostas distintas entre a primeira fase do processo CIP (quando os consumidores contatam as empresas diretamente) e a fase posterior (por meio do órgão de proteção ao consumidor) sugerem que a empresa efetivamente tem práticas distintas nas diferentes fases e prefere que o processo seja definido nessa fase posterior, em que ocorre a intermediação. $\mathrm{O}$ mesmo vale na resposta ao processo FA. Para isso, utilizamos a tática de contagem de temas, no caso pela quantidade de reclamações de cada tipo (MILES; HUBERMAN, I984, p.2I6). Embora não seja possível generalizar, devido à configuração da amostra (não-probabilística), mesmo poucos casos repetidos já indicarão que a prática existe (CRESWELL, I998, p.I54). Poderemos sugerir, neste caso, que há uma mudança de atitude das empresas com a intervenção do Procon.

Esse tipo de análise evidencia o timing da resposta organizacional, que pode ocorrer durante o(s) primeiro(s) contato(s), ou ser postergada mediante respostas que ou negam, ou respondem limitadamente às demandas. A protelação ocorre de maneira que a reclamação venha a ser mediada por órgão de proteção ao consumidor, ou até em uma fase posterior, nos tribunais.

Numa segunda análise, comparamos reclamações classificadas de forma semelhante (segundo a classificação de I a 4 indicada antes) com as respostas recebidas para cada uma (de I a VI). No caso em que determinada associação reclamação-resposta se repete significativamente, é possível sugerir a existência de um tipo de prática para cada tipo de reclamação (CRESWELL, I998).

Cogitamos efetuar o teste não paramétrico do qui-quadrado para estudar a independência ou associação entre classificações, mas por existirem frequências esperadas inferiores a I nas tabelas produzidas a partir da amostra de processos de reclamação colhidos no Procon, não foi possível realizá-lo; convém notar que a junção de categorias de classificação adjacentes, visando contornar essa restrição relacionada à 
frequência estimada, prejudicaria a interpretação do resultado do teste (SIEGEL, I975; COCHRAN, 1954). Em função do exposto, optamos pela análise por meio de porcentagens.

\section{Apresentação e Discussão dos Resultados}

A tabela Ia seguir apresenta a distribuição na amostra colhida, das reclamações, por tipo e área de atuação das empresas:

Tabela I. Distribuição dos processos de reclamações na amostra

\begin{tabular}{|c|c|c|c|r|r|r|r|}
\hline \multirow{2}{*}{$\begin{array}{c}\text { Empresas } \\
\text { (área de atuação) }\end{array}$} & \multicolumn{3}{|c|}{ CIP } & \multicolumn{3}{|c|}{ FA } & \multirow{2}{*}{ Total } \\
\hline Telefonia móvel & $\mathbf{1}$ & $\mathbf{2}$ & $\mathbf{3}$ & $\mathbf{1}$ & $\mathbf{2}$ & $\mathbf{3}$ & \\
\hline Telefonia fixa & 16 & 2 & 13 & - & 3 & 10 & 30 \\
\hline Bancos & 2 & - & 15 & 11 & 3 & - & 48 \\
\hline Financeiras & - & - & 26 & - & - & 13 & 23 \\
\hline Total & 20 & 5 & 65 & 15 & 8 & 27 & 39 \\
\hline
\end{tabular}

Fonte: Pesquisa realizada pelos autores

Nota: Não foram constatadas reclamações do tipo 4

Respostas dadas às reclamações após a intermediação do Procon

A seguir são apresentadas as respostas oferecidas pelas empresas às reclamações constantes dos processos CIP e FA elaborados pelo Procon.

\section{Respostas aos processos CIP}

Uma análise do cruzamento das respostas enunciadas pelas organizações a cada reclamação formulada diretamente pelos clientes, com aquelas enunciadas após a formação dos processos do tipo CIP pelo Procon, possibilitou concluir que o não reconhecimento da reivindicação (resposta tipo I) ocorreu em 78\% dos casos anteriores à interferência do Procon, e que essa resposta permaneceu inalterada somente para cerca de $16 \%$ do total de respostas dos processos CIP (Tabela 3 ). 
Tabela 3. Porcentagem de respostas obtidas antes e depois dos processos CIP

\begin{tabular}{|c|c|c|c|c|c|c|c|}
\hline \multirow{2}{*}{\multicolumn{2}{|c|}{ A N T E S }} & & D & $\mathbf{P}$ & 0 & $\mathbf{S}$ & \\
\hline & & I & II & III & IV & V & VI \\
\hline I & $78 \%$ & $16 \%$ & $18 \%$ & $36 \%$ & - & $8 \%$ & - \\
\hline II & $5 \%$ & $1 \%$ & $1 \%$ & $3 \%$ & & & \\
\hline III & - & - & - & - & - & - & - \\
\hline IV & $5 \%$ & $1 \%$ & $1 \%$ & $1 \%$ & & $1 \%$ & $1 \%$ \\
\hline V & - & - & - & - & - & - & - \\
\hline VI & $12 \%$ & - & $3 \%$ & $7 \%$ & - & $1 \%$ & $1 \%$ \\
\hline TOTAL & $\begin{array}{c}100 \% \\
\text { (90 casos) }\end{array}$ & $18 \%$ & $23 \%$ & $47 \%$ & - & $10 \%$ & $2 \%$ \\
\hline
\end{tabular}

Fonte: Pesquisa realizada pelos autores

Cabe notar, que após a intervenção do Procon (processo CIP), 47\% das reivindicações foram totalmente atendidas, e para mais $35 \%$ dos casos a nova resposta enunciada pelas organizações atende ao menos em parte à demanda do reclamante. Com base nesses resultados, parece viável admitir que a estratégia predominante dessas organizações, quando atendem reclamações de clientes por intermediação do Procon, é responder positivamente às demandas dos reclamantes, mesmo quando a empresa não concorda com suas alegações.

Uma análise detalhada das mudanças nas respostas, as quais antes da intervenção do Procon eram do tipo I, por categoria de empresa amostrada, leva à tabela 4abaixo:

Tabela 4. Porcentagem de respostas inicialmente tipo I alteradas após processo CIP Procon

\begin{tabular}{|l|c|c|c|c|c|c|l|}
\hline Empresas & I & II & III & IV & V & VI & Total \\
\hline $\begin{array}{l}\text { Geral (todas as } \\
\text { empresas da amostra) }\end{array}$ & $20 \%$ & $23 \%$ & $47 \%$ & - & $10 \%$ & - & $\begin{array}{l}100 \%(69 \\
\text { casos })\end{array}$ \\
\hline Telefonia móvel & $47 \%$ & $33 \%$ & $13 \%$ & - & $7 \%$ & - & $\begin{array}{l}100 \%(15 \\
\text { casos })\end{array}$ \\
\hline Telefonia fixa & - & $46 \%$ & $37 \%$ & - & $17 \%$ & - & $\begin{array}{l}100 \%(24 \\
\text { casos })\end{array}$ \\
\hline Bancos & $45 \%$ & $37 \%$ & - & - & $18 \%$ & - & $\begin{array}{l}100 \%(11 \\
\text { casos })\end{array}$ \\
\hline Financeiras & $11 \%$ & - & $89 \%$ & - & - & - & $\begin{array}{l}100 \%(19 \\
\text { casos })\end{array}$ \\
\hline
\end{tabular}

Fonte: Pesquisa realizada pelos autores

A partir do exame da tabela 4, nota-se a existência de estratégias diferenciadas entre as seguidas por categorias de empresa são responder à CIP do Procon: telefonia móvel e bancos são as mais resistentes em promover mudanças em seu posicionamento inicial, apresentando uma porcentagem de manutenção da resposta $(47 \%$ e $45 \%$, 
respectivamente) muito acima da porcentagem verificada para o conjunto das empresas $(20 \%)$. Por outro lado, as financeiras são aquelas que mais respondem totalmente a favor dos clientes (89\% - resposta tipo III, acima da porcentagem verificada para o grupo) e as empresas de telefonia fixa nunca respondem recusando completamente uma demanda (resposta tipo I).

As mudanças em relação às demais respostas iniciais das empresas não serão aqui analisadas, tendo-se em vista a quantidade pouco expressiva de processos envolvidos nos outros tipos de resposta.

\section{Respostas aos processos FA}

De modo semelhante ao que foi feito para processos CIP, cabe fazer um estudo voltado para os processos FA movidos pelo Procon. A tabela 5 seguinte apresenta a distribuição desses $5^{0}$ casos amostrados, revelando a porcentagem de mudanças observadas nos cruzamentos das respostas antes de FAe depois de FA:

Tabela 5. Porcentagem de respostas obtidas antes e depois dos processos FA

\begin{tabular}{|c|c|c|c|c|c|c|c|}
\hline \multicolumn{2}{|c|}{$A N T E S$} & 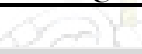 & D & $\mathbf{P}$ & 0 & 1 & \\
\hline & & I & II & III & IV & V & VI \\
\hline I & $50 \%$ & $12 \%$ & $12 \%$ & $24 \%$ & - & $/$ & $2 \%$ \\
\hline ॥ & $14 \%$ & $2 \%$ & $8 \%$ & $4 \%$ & - & - & - \\
\hline III & - & - & - & - & - & - & - \\
\hline IV & $28 \%$ & $6 \%$ & - & $16 \%$ & $4 \%$ & $2 \%$ & - \\
\hline V & $2 \%$ & - & - & $2 \%$ & - & - & - \\
\hline VI & $6 \%$ & $2 \%$ & $2 \%$ & - & - & $2 \%$ & - \\
\hline TOTAL & $\begin{array}{c}100 \% \\
\text { (50 casos) }\end{array}$ & $22 \%$ & $22 \%$ & $46 \%$ & $4 \%$ & $4 \%$ & $2 \%$ \\
\hline
\end{tabular}

Fonte: Pesquisa realizada pelos autores

Da tabela 5 , depreendemos que a maior porcentagem de mudanças ocorreu rumo ao atendimento total das reclamações $\left(46 \%\right.$ - resposta tipo III), e para mais $3_{2}^{2 \%}$ dos casos, a nova resposta enunciada pelas organizações atende ao menos em parte à demanda do reclamante.

Tal como foi feito para os processos CIP, cabe análise detalhada das mudanças verificadas nas respostas de não reconhecimento da reclamação (resposta tipo I), após a intervenção do Procon com os processos FA (Tabela 6): 
Tabela 6. Porcentagem de respostas inicialmente tipo I alteradas após processo FA Procon

\begin{tabular}{|l|c|c|c|c|c|c|l|}
\hline Empresas & I & II & III & IV & V & VI & Total \\
\hline $\begin{array}{l}\text { Geral (todas as } \\
\text { empresas da } \\
\text { amostra) }\end{array}$ & $24 \%$ & $24 \%$ & $48 \%$ & - & - & $4 \%$ & $100 \%(25$ casos $)$ \\
\hline Telefonia móvel & $29 \%$ & $14 \%$ & $43 \%$ & - & - & $14 \%$ & $100 \%(7$ casos $)$ \\
\hline Telefonia fixa & $33 \%$ & - & $67 \%$ & - & - & - & $100 \%(3$ casos $)$ \\
\hline Bancos & $25 \%$ & $62 \%$ & $13 \%$ & - & - & - & $100 \%(8$ casos $)$ \\
\hline Financeiras & $14 \%$ & - & $86 \%$ & - & - & - & $100 \%(7$ casos $)$ \\
\hline
\end{tabular}

Fonte: Pesquisa realizada pelos autores

Notamos com base nessa amostra, que parece haver estratégias diferenciadas por categoria de empresas, quando respondem às FA emitidas pelo Procon: telefonia móvel e fixa são as mais resistentes em promover mudanças em seu posicionamento inicial, apresentando uma porcentagem de manutenção da resposta $(29 \%$ e $33 \%$, respectivamente) muito acima da porcentagem verificada para o conjunto das empresas (24\%). Por outro lado, as financeiras são aquelas que mais respondem totalmente a favor dos reclamantes ( $86 \%$ - tipo III, muito acima da porcentagem verificada para o grupo) e os Bancos são os que menos respondem de modo totalmente favorável aos reclamantes (I3\% - resposta tipo III).

As mudanças em relação às demais respostas iniciais das empresas, não serão aqui analisadas, tendo-se em vista a quantidade pouco expressiva de processos envolvidos em cada um dos outros tipos de resposta.

\section{Respostas ao conjunto total de processos na amostra (CIP e FA)}

Reunindo os resultados obtidos a partir do exame dos processos do tipo CIP e do tipo FA, podemos concluir que as empresas de telefonia móvel são as menos receptivas às reclamações dos clientes, enquanto que as financeiras são as mais receptivas. Evidentemente, tendo-se em vista que a amostra foi colhida por quotas (critério nãoprobabilístico), os resultados obtidos não podem ser generalizados para a população de reclamações feitas às categorias de empresas alvo do presente estudo.

Buscamos também comparar se há um padrão de resposta conforme cada tipo de queixa. Em cada caso, de CIP ou FA, anotamos as respostas posteriores à intermediação do Procon (Tabela 7). 
Tabela 7. Somatório de todas as respostas aos processos CIP e FA, dos quatro setores

\begin{tabular}{|c|c|c|c|c|c|c|c|c|c|c|c|c|c|c|c|c|c|c|}
\hline $\begin{array}{c}\text { Reclamação- } \\
\text { Resposta }\end{array}$ & I-I & 1-II & 1-III & 1-IV & $1-V$ & $1-\mathrm{VI}$ & I-2 & 2-II & 2-III & 2-IV & $2-V$ & $2-\mathrm{VI}$ & 3-I & $3-I I$ & 3-III & 3-IV & 3-V & 3-VI \\
\hline TOTAL & 6 & 12 & 12 & 1 & 3 & 1 & 1 & 3 & 4 & 1 & 3 & 1 & 19 & 18 & 49 & - & 5 & 1 \\
\hline
\end{tabular}

Fonte: Pesquisa realizada pelos autores

Não se pode dizer que, nos casos da nossa amostra, houve uma resposta inquestionável (I a VI) para qualquer tipo de reclamação (I a 3) em qualquer das tabelas. Ou seja, não se constata nenhum tipo de resposta que seja claramente dominante. Notase de fato, ao contrário, uma dispersão. Dessa forma, não seria possível sugerir a existência de uma estratégia dominante segundo o tipo de reclamação.

\section{Ações e propostas para mitigar as reclamações}

Ao se considerar o levantamento documental realizado, percebe-se um quadro onde, com maior ou menor ênfase, as entidades governamentais, os órgãos de defesa do consumidor e a mídia criticam as empresas de telefonia pelos problemas com consumidores que parecem crescer além do que ocorre em outros setores. No setor bancário há também crítica em relação ao aumento das reclamações e, mais especificamente, são destacados alguns dos problemas vividos pelos clientes, que assumem maior importância segundo o período relatado. Entretanto, a fiscalização adicional pelo BC parece prover o setor com maior garantia de resolução de problemas.

O Idec (2OIO) ajuizou uma ação contra a Telefonica, Net, Brasil Telecom e Oi (Telemar) [as três últimas também pertencentes à telefonia], e igualmente contra a Anatel, para garantir a qualidade do serviço de banda larga conforme a oferta. Teste realizado e reclamações mostram que as velocidades verificadas ficam aquém das prometidas. O Idec denuncia os contratos das operadoras que falam que 'fatores externos’ podem influenciar na velocidade de conexão, o que indica uma tentativa de se eximir da responsabilidade de oferecer o serviço.

No setor bancário, o governo federal propõe que, tendo sido atingido um determinado número-teto de denúncias no Procon, seja disparada ação fiscalizadora nos bancos pelo BC (FOLHA DE S. PAULO, I2setembro. 2007; 8fevereiro. 2002), o que soa como uma ameaça ao setor, mas claramente o BC (2OIIa) não tem a capacidade de 
definir quem tem razão em cada queixa, a não ser que haja descumprimento de regulamentações por parte do reclamado, o que não é o caso já que cobranças indevidas e saques não autorizados são algumas das principais queixas registradas e destacadas pelo Procon (FOLHA DE S. PAULO, 28julho. 2OOI) e pelo BC (2OIrb).

De outra parte, a Anatel (2OIO, 2009) e o órgão ligado ao ministério da Justiça, DPDC - Departamento de Proteção e Defesa do Consumidor (2OIO) mostraram, em diferentes intervenções, em distintos momentos, que sua forma de lidar com esses problemas passava no máximo por processos administrativos, cuja atribuição de multa reconhecem ser de aplicação improvável, e descomposturas às empresas em fóruns fechados: "às operadoras, caberão maiores cuidados e maior empenho no trato com os seus clientes, de modo a melhorar os serviços e a percepção que os usuários têm da empresa”. O Inmetro (2006) buscou implantar uma avaliação necessária, porém cedeu às pressões dos interesses: "em virtude da ausência de Regulamentos ou Normas Técnicas que definam critérios para analisar os Serviços de Atendimento aos Consumidores - SACs, o Inmetro definiu, em parceria com as entidades que representam os setores envolvidos [...] uma metodologia específica para a realização da análise."

Quando é a vez das prestadoras de serviço proporem ações corretivas, como foi o caso dos planos apresentados de forma voluntária ao DPDC (MINISTÉRIO DA JUSTIÇA, 20IO; FROUFE, 20IO) pela Tim e Vivo, estas não chegaram a mencionar nenhum ajuste no funcionamento de suas áreas operacional ou administrativa. Propõem, sobretudo maior aproximação dos órgãos de defesa do consumidor.

A mídia, em paralelo, põe em dúvida a isenção da Anatel quando alerta para a contratação de "quatro dos sete presidentes (que) foram trabalhar em operadoras que antes fiscalizaram" (WIZIAK; SOARES, 2OIO).

O fórum de consumidores no site Reclame Aqui (20IIa) confirma mais do que insatisfação, como no exemplo a seguir: “Já sou cliente da Tim há 4 anos e sempre tive problemas, pra (sic) resolver algo precisa insistir muito com a mesma! Só não deixo por causa dos pacotes pra (sic) fixo, que a concorrência pré não oferece”. Contra os bancos, igualmente, os termos são contundentes para evidenciar os erros dos reclamados: 
"Débito sem autorização" ou "Atendimento zero" ou "Cobrança indevida" (RECLAME AQUI, 2OIIb).

\section{Discussão}

Vimos antes que apesar do crescente número de reclamações registradas na Fundação Procon-SP, apenas uma pequena fração dos consumidores insatisfeitos inicia processos de reclamação. Desta forma, temos que o número de reclamações seria ainda mais elevado caso todas as insatisfações fossem anotadas. A maioria destes consumidores dirige-se diretamente às empresas reclamadas antes de buscar o apoio de um intermediário.

Pudemos ver igualmente que se esses números aumentaram, isso se deve ao fato de que as empresas não alteraram seus procedimentos no atendimento às reclamações.

Considerando as duas proposições formuladas anteriormente (tópico 3), para verificar se as empresas desenvolvem estratégias deliberadas de atendimento a queixas dos consumidores, pudemos concluir que quando as denúncias chegam ao Procon, a maioria das demandas dos consumidores são aceitas. Com relação à Telefonica, por exemplo, o Procon por meio do Ministério Público ajuizou ação contra ela e afirmou que "a Telefonica tem uma peculiaridade: alto índice de resolução no Procon-SP. Isto é, os consumidores sempre tentam resolver o problema diretamente (o que é recomendável), mas não conseguem.” (REVISTA PROCON-SP, 2009, p.23). Essa percepção parece confirmar a conclusão do levantamento quantitativo anterior. Segundo o superintendente do Procon, a empresa suscita constantemente novos problemas (FOLHA DE S. PAULO, 2009).

Assim, é possível supor que, para pelo menos um determinado percentual de queixas, a estratégia seja a de omitir qualquer resposta ou oferecê-las limitadamente, contando com que o consumidor desista de suas demandas ao longo do tempo. Essa postura repete-se nos quatro setores examinados, apesar de, como pudemos mostrar, haver diferenças nas práticas entre estes em suas respostas aos consumidores anteriores à intervenção do Procon.

$\mathrm{Na}$ segunda proposição que examinou as respostas associadas aos diversos tipos de queixa para confirmar se alguma era prevalente, percebemos que estas recebem uma 
diversificada gama de respostas. Assim, não é possível identificar que haja aí estratégias específicas.

A análise documental por sua vez veio reforçar a ideia de que há, de fato, uma estratégia de recusa visando adiamento de uma parcela das demandas, até que venham eventualmente a ser tratadas pelos órgãos de proteção ao consumidor, sobretudo o Procon. Isso sugere que as empresas estão dispostas a mostrar boa vontade para estes órgãos, seja porque queiram preservar sua imagem, pela publicidade negativa que poderia ser gerada, ou porque a porcentagem de reclamações neste estágio já seja baixa.

Não se pode dizer desta forma que as empresas priorizam os clientes em todas as ocasiões ou que procuram sempre responder com justiça a seus reclamos conforme sugeriam os modelos teóricos examinados antes (GILLY, I987; DOLINSKY, I994; TAX et al., I998; MAXHAM; NETEMEYER, 2002; 2003).

Por outro lado, na medida em que constatamos que uma parte das demandas é de fato postergada ou atendida de forma insatisfatória, o que leva à intermediação do Procon se o consumidor decide prosseguir com o caso, pode-se dizer que a prática repetida constitui uma estratégia empresarial de caráter não-competitivo (MINTZBERG, I978). Trata-se de uma percepção da realidade que leva em consideração as restrições impostas pela gestão empresarial ao tratamento das reclamações.

\section{Conclusões e Considerações Finais}

A partir da proposta deste trabalho, de analisar se as práticas de atendimento seguiam estratégias deliberadas ou se o atendimento baseava-se no esforço de atender todos as demandas consideradas plausíveis, a fim de manter a base de clientes, realizamos uma pesquisa com processos de reclamação anotados no Procon, em relação a empresas de quatro setores da economia: telefonia fixa, telefonia móvel, bancos e financeiras.

Pudemos concluir que quando as denúncias chegam ao Procon, a maioria das demandas dos consumidores é aceita, e também que não há um padrão típico de resposta para cada modalidade de reclamação.

O aumento acentuado do número de queixas contra as mesmas empresas, ano após ano, pode indicar que os consumidores, as agências de proteção e os departamentos governamentais não têm sido capazes de sensibilizar as empresas para melhorar seu 
atendimento de reclamações. Podemos concluir desta forma que os reclamantes, as agências de proteção e o governo ainda não foram capazes de mudar a lógica como as empresas lidam com as queixas, tratando-as caso a caso e fazendo uso de táticas de adiamento.

As empresas que compõem os referidos setores possuem muita força no mercado, tanto por serem poucas empresas ofertantes dos respectivos produtos e serviços em cada um desses setores da economia (cada vez mais concentrados), como pela legislação e regulamentação que as ampara.

Os resultados deste trabalho de pesquisa mostraram que o atendimento de reclamações, de um lado, ao não mudar para lidar com o número crescente de reclamações, e de outro, ao ser constatado que parte das reclamações é estrategicamente postergada até chegar ao Procon, não corresponde às orientações de uma grande parcela dos textos que abordam o comportamento do consumidor e gestão de queixas, como vimos em seção precedente, ao proporem procedimentos e estruturas que permitam atender às reclamações de modo a conservar o consumidor satisfeito.

A decisão estratégica nessa área não parece ser tomada no domínio exclusivo do marketing, mas pode resultar da combinação de várias outras decisões funcionais, que podem em muitos casos não acompanhar a orientação que parece mais apropriada ao marketing.

É necessário salientar que as conclusões não são generalizáveis para a população de reclamações, pois o estudo baseou-se em amostra não probabilística de processos registrados no Procon.

Finalmente, o trabalho aponta para a realização de futuras pesquisas empíricas que possam melhorar a compreensão do comportamento empresarial nessa área. Este tipo de estudo poderia ser replicado em outros setores econômicos e, se possível, com base em amostra representativa, que permitisse a generalização das conclusões. Também, é possível pensar em analisar qual o nível de desistência por parte dos consumidores, antes de buscar a intermediação dos órgãos de proteção, e suas razões, uma vez que temos indicações anteriores de que esse número é elevado. A realização de tal estudo permitiria analisar ainda se há durante os primeiros contatos estratégias de como responder aos reclamantes. Além disso, outra questão relevante é avaliar e compreender 
a percepção das empresas quanto às contribuições e restrições trazidas pelas agências de proteção.

\section{Referências}

AAKER, D.; DAY, G. S. A Guide to Consumerism. In: AAKER, D.; DAY, G. S. (eds.) Consumerism: Search for the Consumer Interest. Madison: Free Press, 1982, p.2-2O.

ANATEL. Fórum de valorização do atendimento aos usuários é realizado em Brasilia, 2010.

Disponível em

$<$ http://www.anatel.gov.br/Portal/exibirPortalNoticias.do?acao $=$ carregaNoticia\&codigo $=2 \mathrm{I} 698>$. Acesso em I8 Fev 20 II.

ANATEL. Anatel exige mais qualidade na telefonia celular, 2009. Disponível em $<$ http://www.anatel.gov.br/Portal/exibirPortalNoticias.do?acao=carregaNoticia\&codigo=I8oog>. Acesso em I7 Fev 2OII.

ANATEL.Anatel abre 1723 processos administrativos contra empresas de telefonia fixa, 2000.

Disponível em

$<$ http://www.anatel.gov.br/Portal/verificaDocumentos/documento.asp?numeroPublicacao $={ } 3972$ \&assuntoPublicacao=Anatel\%2Oabre\%2OI723\%2oprocessos\%2Oadministrativos\%2ocontra\%2Oem presas\%2ode\%2otelefonia\%2ofixa\&caminhoRel=null\&filtro=I\&documentoPath=biblioteca/release s/200o/release_2O_O7_2OOO(4).pdf>. Acesso em I5 Fev 2OII.

BANCO CENTRAL.Reclamações e denúncias contra bancos, consórcios, cooperativas,2OIIa.

Disponível em

<http://www.bcb.gov.br/pre/portalCidadao/bcb/reclamacaoDenuncia.asp?idpai=PORTALBCB $>$. Acesso em 22 Abr 20 III.

BANCO CENTRAL.Reclamações procedentes em Março/2011, 20Irb. Disponível em $<$ https://www3.bcb.gov.br/ranking/idxrc.do>. Acesso em 22 Abr 20 OII.

BOLFING, C.P. How Do Customers Express Dissatisfaction and What Can Service Marketers Do about It? Journal of Services Marketing, v.3, n.2, p.5-23, I989

BRAFF, A.; LAOGUE, S. M. Mobile’s dissatisfied customers. McKinsey Quarterly, v.3, p.IO-I2, 2004

CHAUVEL, M. A.; GOULART, V. C. Como gerar valor para os clientes poer meio dos serviços de atendimento ao consumidor: o que mostram as pesquisas. CADERNOS EBAPE-BR 5(4), Dez, 2007. Disponível em

$<$ http://app.ebape.fgv.br/cadernosebape/asp/dsp_texto_completo.asp?cd_pi=549662 $>$. Acesso em o? Mai 20 II

CHAUVEL, M. A. Consumidores Insatisfeitos: uma oportunidade para as empresas. R. Janeiro: Mauad, 2000

CRESWELL, J. W. Qualitative Inquiry and Research Design: Choosing Among Five Traditions. Thousand Oaks, California: Sage, r998 
DAY, G.S. A empresa orientada para o mercado: compreender, atrair e manter clientes valiosos. P. Alegre: Bookman, 2OOI

DOLINSKY, A. L. A Consumer Complaint Framework with Resulting Strategies: An Application to Higher Education. Journal of Services Marketing, v.8, n.3, 27-39, I994

ESTADÃO.Telefônica: reclamantes no Procon são apenas o,o4\% dos clientes, 2007. Disponível em $<$ http://www.estadao.com.br/arquivo/economia/2007/not200703I5pior77.htm>. Acesso em 7 Jan 2009

FAIRCLOUGH, N. Discurso e Mudança Social. Brasília: UnB, 2OOI

FOLHA DE S. PAULO. Telefónica lidera queixas pelo $3^{\circ}$ ano seguido, 2009. Disponível em <http://wwwi.folha.uol.com.br/fsp/cotidian/ffI4032009I4.htm>. Acesso em I3 Mar 2OII

FOLHA DE S. PAULO. Governo quer teto de denúncias que dispare ação fiscalizatória, I2 set. 2007. Disponível em <http://wwwi.folha.uol.com.br/fsp/dinheiro/fir209200726.htm>. Acesso em I2 Abr 2OII

FOLHA DE S. PAULO.BC e Procons vão dividir o trabalho de apurar reclamações contra bancos, 8 fev. 2002. Disponível em <http://wwwi.folha.uol.com.br/fsp/dinheiro/fio8o22002I6.htm>. Acesso em I2 Abr 2OII

FOLHA DE S. PAULO.Cobrança indevida de tarifa é a maior queixa, 28 jul. 20OI. Disponível em $<$ http://wwwI.folha.uol.com.br/fsp/dinheiro/fi2807200I29.htm >. Acesso em I2 Abr $2 \mathrm{OII}$

FORNELL, C.; WERNERFELT, B. Defensive Marketing Strategy by Customer Complaint Management: A Theoretical Analysis. Journal of Marketing Research, v.24 (Nov), p.337-46, I987 FORNELL, C.; WESTBROOK, R. The Vicious Circle of Consumer Complaints. The Journal of Marketing, v.48 (3), p.68-78, summer 1984

FROUFE, C. Empresas fazem acordo para reduzir reclamações. O Estado de São Paulo, Caderno de Negócios, p. BI5, Abril 27, 2010

GARRETT, D. E. The Types of Information Contained in Company Reliability Reports from the Better Business Bureau. The Journal of Consumer Affairs, v.40 (I), 2006

GILLY, M. C. Postcomplaint Processes: From Organizational Response to Repurchase Behavior. The Journal of Consumer Affairs, v.2I (2), p. 293-313, 1987

GRANT, R. M. Corporate Strategy: Managing Scope and Strategy Content. In: PETTIGREW, A.; THOMAS, H.; WHITTINGTON, R. (eds) Handbook of Strategy and Management. London: Sage, 2002, cap. 4

GREENWOOD, R.; HININGS, C. R. Understanding Radical Organizational Change: Bringing Together the Old and the New Institutionalism. Academy of Management Review, v. 2I, n.4, p.IO2254 , out 1996

HOFFMAN, K.D.; KELLEY, S.W.; ROTALSKY, H.M. Tracking Service Failures and Employee Recovery Efforts. Journal of Services Marketing, v.9 (2), p.49-6I, 1995

HOMBURG, C.; FÜRST, A.; KOSCHATE, N. On the importance of complaint handling design: a multi-level analysis of the impact in specific complaint situations. Journal of the Academy of Marketing Science, 38, p.265-287, 2010 
HOMBURG, C.; FÜRST, A. How Organizational Complaint Handling Drives Customer Loyalty: An Analysis of the Mechanistic and the Organic Approach. Journal of Marketing, v.69 (Jul), P.95-II4, 2005

IDEC. Idec entra com ação contra teles e Anatel para garantir velocidade de banda larga, $20 \mathrm{OIO}$. Disponível em <http://www.idec.org.br/emacao.asp?id=2I89>. Acesso em I5 Fev 2OII

INMETRO. Relatório sobre Análise em SAC de Telefonia Fixa e Móvel, 20o6. Disponível em $<\mathrm{http}$ ///www.inmetro.gov.br/consumidor/produtos/SAC_Telefonia.pdf $>$. Acesso em 27 Out 2010

IPEA-Instituto de Pesquisa Econômica e Aplicada. Produto Interno Bruto, 20og. Disponível em $<$ http://www.ipeadata.gov.br/ipeaweb.dll/ipeadata?SessionID $=\mathrm{I} 4697 \mathrm{IO} 77$ O \&Tick $={ }_{2} 626{ }_{5} 5956343$ \&VAR_FUNCAO=Qua_Itens(I4O73I70o8)\&Mod=M $>$. Acesso em 30 Dez 20 IO

LAWRENCE, T. B. Institutional Strategy. Journal of Management, v. 25, n.2, p. I6I-I88, I999

MAXHAM, J. G.; NETEMEYER, R. G. Firms Reap What They Sow: The Effects of Shared Values and Perceived Organizational Justice on Customers' Evaluations of Complaint Handling. Journal of Marketing, v.67 (Jan), p.46-62, 2003

MAXHAM, J. G.; NETEMEYER, R. G. A Longitudinal Study of Complaining Customers' Evaluations of Multiple Service Failures and Recovery Efforts. Journal of Marketing, v.66 (Out), p. 57-7I, 2002

MEDEIROS, E. Fórum Consumidor Moderno propõe soluções na relação varejo X indústria. NoVarejo, i7 Nov 2OIo. Disponível em <http://www.cmnovarejo.com.br/inovacao/melhorespraticas/II3o-forum-consumidor-moderno-tambem-propos-solucoes-na-relacao-varejo-X-industria$>$. Acesso em I3 Dez

MILES, M. B.; HUBERMAN, A. M. Qualitative Data Analysis: A Sourcebook of New Methods. B. Hills, CA: Sage, I984

MINISTÉRIO DA JUSTIÇA. Proposta dos fornecedores para atendimentos, 20IO. Disponível em $<$ http://portal.mj.gov.br/main.asp?View $=\{80 F 6$ I48E-C535-4E4D-Bi8E-

D2915905905o $\&$ BrowserType $=$ NN\&LangID $=$ pt-br\&params $=$ itemID\%3D $\left\{8928 \mathrm{EF}_{\text {I9-o88F-45o8- }}\right.$

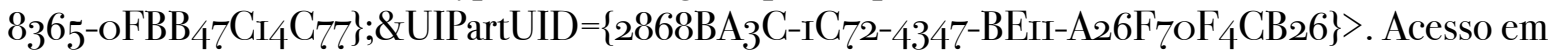
25 Mai $201 \mathrm{II}$

MINTZBERG, H. Patterns in Strategy Formation, Management Science, v.24, n.9: p.934-948, 1978

OFCOM, Office of Communications.Consumer Complaints Review. UK, Jul Io, 2008

PEARSON, M. M. A Note on Business Replies to Consumer Letters of Praise and Complaint. Journal of Business Research, Fev, p.6I-67, 1976

PETTIGREW, A.; THOMAS, H.; WHITTINGTON, R. Strategic Management: The Strengths and Limitations of a Field. In: PETTIGREW, A.; THOMAS, H.; WHITTINGTON, R. (eds) Handbook of Strategy and Management. London: Sage, 2002

PORTER, M. What is Strategy? Harvard Business Review: p.6I-78, nov-dec, I996

PROCON-SP. Cadastro de Reclamações Fundamentadas: período 2009 Kit de Imprensa, 2OIO. S. Paulo: Secretaria da Justiça e da Defesa da Cidadania. Disponível em 
$<$ http://www.procon.sp.gov.br/pdf/acs_cadastro_de_reclamacoes_fundamentadas_20o9.pdf $>$. Acesso em I5 Fev $201 \mathrm{I}$

PROCON-SP. Cadastro de Reclamações Fundamentadas: período 2008. S. Paulo: Secretaria da Justiça e da Defesa da Cidadania, 2009a

PROCON-SP. Empresas Reclamadas, 2009b. Disponível em $<$ http://www.procon.sp.gov.br/noticia.asp?id=IO77 $>$. Acesso em 30 Dez 20 II

PROCON-SP. Cadastro de Reclamações Fundamentadas: período 2007. S. Paulo: Secretaria da Justiça e da Defesa da Cidadania, 2008a

PROCON-SP. Cadastro de Reclamações Fundamentadas: período 20o6. S. Paulo: Secretaria da Justiça e da Defesa da Cidadania, 2007

PROCON-SP. Cadastro de Reclamações Fundamentadas: período 2005. S. Paulo: Secretaria da Justiça e da Defesa da Cidadania, 2006

RECLAME AQUI.Tópicos de reclamação da Tim Celular, 20IIa. Disponível em $<$ http://www.reclameaqui.com.br/comunidades/comunidade/?empresa $={ }_{2} 85_{2} \&$ action $=$ topics $>$. Acesso em I8 Fev 2OII

RECLAME AQUI. Todas as reclamações contra o Santander, 20IIb. Disponível em $<$ http://www.reclameaqui.com.br/indices/lista_reclamacoes $/$ ? id $=98 \& t \mathrm{t}=9403$ f 4 cocd 5 af6rc48554I e9444950co69c79ffa\&subtp=c92agbc34Id739044ff540066Id44a6oa8o8be22>. Acesso em I3 Abr 2OII

REVISTA PROCON-SP. MP quer que Telefónica indenize seus consumidores. Jan-Fev, p. 24-25, 2009

RICHINS, M.L. Consumer Complaining Process: A Comprehensive Model. In: DAY, R.; HUNT, H.K. (eds.) New Dimensions of Consumer Satisfaction and Complaining Behavior, ${ }_{3}$ RD ANNUAL CONFERENCE ON CONSUMER SATISFACTION/ DISSATISFACTION AND COMPLAINING BEHAVIOR, Chicago, 5-7 October 1978, School of Business, Indiana University, p.502-o6, I979

SINGH, J. Voice, Exit, and Negative Word-of-Mouth Behaviors: An Investigation across Three Service Categories. Journal of the Academy of Marketing Science, v.I8, n.I, p.I-I5, I99O

TARP-Technical Assistance Research Program. Consumer Complaint Handling in America: An Update Study, White House Office of Consumer Affairs, Washington DC, I986

TAX, S. S.; BROWN, S. W.; CHANDRASHEKARAN, M. Customer Evaluations of Service Complaint Experiences: Implications for Relationship Marketing. The Journal of Marketing, v.62, n.2, p.6o-76, Abr $199^{8}$

WHITTINGTON, R. Oque é Estratégia. S. Paulo: Pioneira Thomson, 2002

WIZIAK, J ; SOARES, P. Empresas têm relação íntima com reguladoras. Folha de S. Paulo, 23 Mai. 2OIO. Disponível em<http://wwwi.folha.uol.com.br/fsp/mercado/me23052OIOOI.htm $>$. Acesso em 24 Mai 20 II 